\title{
Otras disposiciones de interés para la Administración Autónomica
}

\section{FUNCIÓN PÚBLICA}

DECRETO 228/2006, de 26 de diciembre, por el que se modifica parcialmente la Relación de Puestos de Trabajo de la Administración General de la Junta de Andalucía correspondiente a la Consejería de Medio Ambiente y se integra y adscribe a puestos de la misma al personal traspasado de los Parques Nacionales de Doñana y Sierra Nevada por el Real Decreto 712/2006, de 9 de junio.

BOJA número 6 de 09 de Enero de 2007

DECRETO 7/2007, de 9 de enero, por el que se modifica parcialmente la relación de puestos de trabajo de la Administración General de la Junta de Andalucía correspondiente a la Consejería de Economía y Hacienda.

BOJA número 16 de 22 de Enero de 2007

ORDEN de 18 de enero de 2007, de la Dirección General de Función Pública, por la que se modiFica parcialmente la relación de puestos de trabajo de la Administración General de la Junta de Andalucía correspondiente al Centro Andaluz de Arte Contemporáneo, en cumplimiento de la sentencia que se cita.

BOJA número 25 de 02 de Febrero de 2007

DECRETO 17/2007, de 16 de enero, por el que se modifica parcialmente la relación de puestos de trabajo de la Administración General de la Junta de Andalucía correspondiente a la Consejería de Justicia y Administración Pública.

BOJA número 29 de 08 de Febrero de 2007

DECRETO 16/2007, de 16 de enero, por el que se modifica parcialmente la Relación de Puestos de Trabajo de la Administración General de la Junta de Andalucía correspondiente a la Consejería de Educación.

BOJA número 31 de 12 de Febrero de 2007

ORDEN de 16 de febrero de 2007, por la que se suprime la categoría de Psicólogo y se establece el procedimiento de integración directa en la cate- 
goría de Facultativo Especialista de Área de Psicología Clínica en el Servicio Andaluz de Salud

BOJA número 39 de 22 de Febrero de 2007

DECRETO 36/2007, de 6 de febrero, por el que se definen los puestos de trabajo Docentes de los Centros de Educación Permanente, se establece su forma de provisión y se regula la coordinación provincial de Educación Permanente.

BOJA número 44 de 02 de Marzo de 2007

\section{ORGANIZACIÓN ADMINISTRATIVA}

DECRETO 6/2007, de 9 de enero, por el que se aprueba el Reglamento de Funcionamiento interno del Consejo de la Juventud de Andalucía.

BOJA número 19 de 25 de Enero de 2007

ACUERDO de 20 de febrero de 2007, del Consejo de Gobierno, por el que se aprueba el Plan General de Inspección para el año 2007.

BOJA número 47 de 07 de Marzo de 2007 